\title{
The effects of television and Internet food advertising on parents and children
}

\author{
Simone Pettigrew ${ }^{1, *}$, Liudmila Tarabashkina ${ }^{2}$, Michele Roberts ${ }^{3}$, Pascale Quester ${ }^{2}$, \\ Kathy Chapman ${ }^{4}$ and Caroline Miller ${ }^{5}$ \\ 'UWA Business School and UWA School of Sport Science, Exercise and Health, 35 Stirling Highway, Crawley, \\ WA 6009, Australia: ${ }^{2}$ University of Adelaide, Adelaide, South Australia, Australia: ${ }^{3}$ UWA Business School, \\ Crawley, Western Australia, Australia: ${ }^{4}$ Cancer Council New South Wales, Woolloomooloo, New South Wales, \\ Australia: ${ }^{5}$ South Australian Health and Medical Research Institute, University of Adelaide, Adelaide, \\ South Australia, Australia
}

Submitted 10 August 2012: Final revision received 11 March 2013: Accepted 12 March 2013: First published online 1 May 2013

\begin{abstract}
Objective: The current study examined the impact of television and Internet food advertising on Australian parents and children.

Design: Parents and their children aged 8 to 14 years were exposed to a television advertisement, an Internet advertisement or a control picture for four commonly advertised energy-dense, nutrient-poor foods.

Setting: Online web panel survey, Australia.

Subjects: Parents ( $n$ 1302) and their children aged 8 to 14 years $(n 1302)$.

Results: After a single exposure to each advertisement, parent respondents in the two exposure conditions evaluated the products more favourably, had a greater desire to consume the products and thought the product could be consumed more frequently than those in the control condition. Similar trends were observed among children, although the differences were statistically significant only for the frequency of food consumption in the Internet advertisement condition and the evaluation of one product.

Conclusions: The results have implications for assumptions of adults' immunity to advertising. This is of particular importance in efforts to address child obesity and the reliance on parents to mediate the effects of food advertising.
\end{abstract}

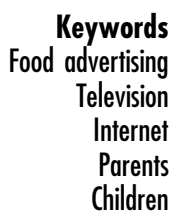

There are growing concerns that food advertising is contributing to the obesity epidemic that is adversely affecting individuals and societies and is forecast to drain nations' health-care budgets ${ }^{(1-3)}$. Much of the focus on addressing obesity is centred on child obesity because of the difficulty of treating obesity once it is established and the tendency for child overweight to continue into adulthood $^{(4,5)}$. Major reviews have concluded that the marketing of energy-dense, nutrient-poor (EDNP) foods is an important contributor to an environment that promotes child obesity ${ }^{(6-9)}$. In response, in some countries public policy makers have enacted legislation to limit children's exposure to advertising for EDNP foods and the food industry has introduced voluntary codes of conduct that prevent signatory organisations from promoting EDNP foods to children ${ }^{(10)}$.

In Australia, the context of the present study, a combination of mandatory and voluntary regulations applies to food advertising. The coverage of these regulations relates mainly to television advertising. The mandatory Children's Television Standards ${ }^{(11)}$ specify times at which advertising can be shown and nominate conditions under which food and beverage products can be advertised. They stipulate that no advertising can be broadcast during 'P' programming, which encompasses programmes designed for pre-school children, and limit the quantity and nature of advertisements that can be broadcast during 'C' programming, which includes programmes designed for children up to 14 years of age. For example, during ' $\mathrm{C}$ ' programmes alcoholic beverages cannot be advertised and any promotion of food products cannot provide misleading information about the nutritional profile of the products.

In addition, two voluntary codes of conduct were implemented by the food industry in 2009: the Responsible Children's Marketing Initiative ${ }^{(12)}$ and the Australian Quick Service Restaurant Industry Initiative for Responsible Advertising and Marketing to Children ${ }^{(13)}$. These codes commit signatory organisations to promoting only healthy foods to children up to 12 and 14 years of age, respectively. Evaluation studies conducted since their implementation suggest that these voluntary codes have been unsuccessful in substantially reducing Australian children's exposure to television advertising for EDNP foods ${ }^{(14,15)}$. 
The focus of regulations on television advertising in Australia is similar to the situation in other countries, with the outcome being that other media remain largely unregulated around the world ${ }^{(10,16-18)}$. While television continues to dominate the advertising strategies of food marketers ${ }^{(19,20)}$, the mass popularisation of the Internet and the associated migration of a growing proportion of advertising budgets to this medium necessitate more extensive consideration of Internet advertising ${ }^{(7,19)}$. In line with other forms of advertising, Internet advertising has been found to be able to attract attention ${ }^{(21)}$, enhance brand recognition and awareness ${ }^{(22)}$ and increase the probability of repeat purchase ${ }^{(23)}$. Specifically in terms of food marketing, however, there is little evidence to date of the absolute and relative effectiveness of Internet advertising, and this lack of evidence constrains policy making ${ }^{(3,16,19,24,25)}$. Given the amount of time children now spend on the Internet and the greater blurring of boundaries between content and advertising in online contexts, it has been argued that Internet food advertising requires particular attention in efforts to address the negative effects of EDNP food marketing ${ }^{(3,19,25-27)}$.

Existing advertising regulations are based on evidence that food advertising can influence children's food preferences and choices ${ }^{(28)}$. Specifically, higher levels of television viewing and exposure to food advertising among children have been found to be associated with more favourable attitudes to EDNP foods ${ }^{(29)}$ and greater intake of EDNP foods and lower intakes of fruits and vegetables ${ }^{(30-32)}$. It has been noted that calls for interventions to protect children from advertising typically assume that children will be able to withstand the coercive effects of advertising once their cognitive defences mature and hence that they only need protection until they can understand the nature and intent of advertising ${ }^{(3,33)}$. However, even an understanding of persuasive intent can fail to protect older children from experiencing increased desire for products as a result of advertising exposure ${ }^{(34,35)}$.

Adults, by comparison, are typically considered to be 'competent consumers' who are sceptical of advertising and hence able to activate appropriate cognitive defences ${ }^{(24)}$. However, there is a growing body of work demonstrating that advertisements for EDNP foods can also influence adults' perceptions of the desirability and appropriateness of such foods ${ }^{(36,37)}$. Like children, adults can fail to activate the cognitive resources necessary to prevent automatic acceptance of the messages conveyed (for a review see Harris et $a l l^{(3)}$ ). This is likely to be at least partially attributable to the subconscious effects of advertising that occur through exposure and repetition rather than deliberate cognitive processing ${ }^{(38,39)}$.

The effect of food advertising on adults is important because of the implications for the weight status of both parents and the children who are dependent upon their food choices. Parents influence their children's diets through their critical roles as food providers and modellers of food consumption ${ }^{(40,41)}$. More research is needed to elucidate the effects of food advertising on both children and their parents to ensure that both groups are appropriately catered for in the development and implementation of relevant public policies ${ }^{(3,33)}$.

In summary, there are knowledge deficits in the areas of parents' and children's susceptibility to food marketing and the relative effectiveness of food advertising on television and the Internet. The present study addresses these knowledge gaps by investigating the effects of television and Internet food advertising on both parents and children in the Australian context.

\section{Experimental methods}

\section{Sample}

The population of interest was children aged 8 to 14 years and their parents. The minimum age of 8 years for the children reflected the need for respondents to be capable of responding to an online questionnaire. The maximum age of 14 years was based on John's ${ }^{(42)}$ proposition that up until this age children may be unable to activate the cognitive defences required to withstand advertising effects. Parents could be of any age, as long as they had children within the specified age range. Only one child per parent was invited to participate in the study.

Respondents were sourced from an online panel provider with access to a large number of Australians of varying demographic profiles. Panel members with children in the nominated age group were invited to participate in the survey. Quota sampling was then used to achieve equal representation of children by gender and age over the entire child sample and between the intervention and control groups.

\section{Materials and procedure}

Six versions of the questionnaire were developed - three for the parents and three for the children. One parent and one child questionnaire featured four television food advertisements, one parent and one child questionnaire featured Internet advertisements for the same four products, and one parent and one child questionnaire showed pictures of the food products that served as the control condition. The four branded food products featuring in all six questionnaires were fried chicken, popcorn, a snack bar and confectionery. These products were selected to cover a broad range of advertised foods that are likely to be popular with children and that have high levels of fat, sugar and/or salt (as per UK Food Standards Agency thresholds $\left.{ }^{(43)}\right)$.

The stimuli for the television advertisements were $30 \mathrm{~s}$ advertisements that had aired on television during the previous 12 months. The fried chicken advertisement depicted a family eating the chicken together at dinner, the popcorn advertisement showed a mother making 
popcorn for her child who was playing outside on a trampoline, the snack bar advertisement showed children eating the product at school, and the confectionery advertisement depicted an athlete eating the sweets after a training session and talking about her enjoyment of them. The stimuli for the Internet advertisements were webpages featuring each of the products. The fried chicken Internet advertisement was a Facebook page that included a picture of the product and comments from fans paying tribute to it. The popcorn webpage showed images of the product and a child playing outside on a trampoline, the snack bar advertisement showed multiple pictures of the product along with text that emphasised the taste and 'fun' attributes of the product, and the confectionery webpage featured an image of an athlete (the same person depicted in the television advertisement) eating the sweets along with written endorsements from athletes and sporting organisations. The stimuli for the control group were static pictures, identical in size, of each food product.

The items included in the questionnaires were based on those used in Grier et al.'s ${ }^{(37)}$ study of parental perceptions of fast-food advertising and Jones and Fabrianesi's $^{(44)}$ study of children's and parents' perceptions of advertising. They included items relating to desire for the advertised products ('Would you like to have this food to eat?'; three response options for both parents and children: $1=$ 'not at all', $2=$ 'a little', 3 = 'a lot') and perceived appropriate frequency of consumption ('How often is it okay for people to have this product?'; five response options for parents ranging from $1=$ 'never' to $5=$ 'daily' and three response options for children: $1=$ 'never', $2=$ 'a little', 3 = 'a lot'). Demographic questions asked of parents included gender, age, income, education, family structure (one- or two-parent household) and self-reported weight and height (to enable calculation of BMI). Children were only asked to report gender and age.

Each parent-child dyad was exposed to the same media (television advertisement, Internet advertisement or picture) and to a total of four advertisements, one for each food product. All respondents were shown one advertisement/picture and then asked a series of questions about the extent to which they would like to consume the food, their perceptions of appropriate consumption frequency and their evaluations of the food across multiple criteria (e.g. taste and healthiness). They were then shown the next advertisement/picture and asked the same series of questions, and so on. The parents and children were asked largely the same questions, varying somewhat in wording to cater to the different cognitive and language abilities of the two groups.

Prior to administration, the questionnaire items were tested for suitability in six focus groups comprising varying combinations of parents and children ( $n$ 64). Two of the groups included only children (one group of boys and one group of girls), two groups included only parents (one group of mothers and one group of fathers) and two groups combined parents and children (one group of mothers and their children and one group of fathers and their children). During the groups, the participants completed a version of the questionnaire and then each item was discussed to assess how it was interpreted and whether there was any confusion about its meaning or relevance. The focus group findings indicated that the items were interpreted correctly, and only minor modifications were made to some of the items to enhance comprehension.

The online survey was conducted in December 2010. Ethics clearance for the study was obtained from the University of Western Australia Human Research Ethics Committee. Parents agreeing to participate in the study were asked to complete their questionnaire before passing the computer over to their children, who were also asked for consent prior to commencing. It was necessary for each item to be addressed before the respondent could progress to the next page, resulting in a complete data set from all respondents.

\section{Analysis}

Several measures were developed for the present study. To estimate parents' and children's desire to consume foods ('Would you like to have this food to eat?'), the answer scores across the four food products were summed and then divided by the number of products included. A similar process was used to create an aggregate measure for respondents' perceptions about appropriate consumption frequency ('How often is it okay for people to have this product?'). Finally, parents were asked to rate each product on the five attributes of healthy, tasty, fun, new and convenient, while children were asked to rate the products on four of these attributes, with the exclusion of convenient which was considered to be less relevant for children. A product evaluation measure was created for each food product by summing the scores across various attributes and then dividing by the number of attributes. These aggregate measures allowed estimation of the overall effects of advertising across the range of foods products included in the study.

Data were analysed using the ANOVA method whereby one-way factorial ANOVA were performed to identify differences in the desire to consume the advertised products, perceived appropriate consumption frequency and product evaluations between the television and Internet exposure groups and the control group. Differences in responses depending on the type of exposure were also examined separately for boys and girls and children belonging to the same age category (one-way factorial ANOVA). The analyses were performed using the statistical software package SPSS version $17 \cdot 0$.

\section{Results}

The sample profile is shown in Table 1. In total, 2604 respondents participated in the survey, with 33\% 
Table 1 Sample composition: parents ( $n$ 1302) and their children ( $n$ 1302) aged 8-14 years participating in an online web panel survey, Australia, December 2010

\begin{tabular}{|c|c|c|}
\hline & $n$ & $\%$ \\
\hline Parents & 1302 & 100 \\
\hline \multicolumn{3}{|l|}{ Gender } \\
\hline Male & 434 & 33 \\
\hline Female & 868 & 67 \\
\hline \multicolumn{3}{|l|}{ Age } \\
\hline $26-35$ years & 250 & 19 \\
\hline $36-45$ years & 743 & 57 \\
\hline$\geq 46$ years & 309 & 24 \\
\hline \multicolumn{3}{|l|}{ Income } \\
\hline$<\$ A U 30000$ & 84 & 6 \\
\hline$\$ A \cup 30001-49999$ & 152 & 12 \\
\hline \$AU 50001-74999 & 262 & 20 \\
\hline \$AU 75001-99999 & 339 & 26 \\
\hline$\geq \$ A U 100000$ & 465 & 36 \\
\hline \multicolumn{3}{|l|}{ Education } \\
\hline Secondary school & 393 & 30 \\
\hline Undergraduate qualification & 688 & 53 \\
\hline Postgraduate qualification & 221 & 17 \\
\hline \multicolumn{3}{|l|}{ Family structure } \\
\hline Two-parent family & 1046 & 80 \\
\hline One-parent family & 182 & 14 \\
\hline Other/not specified & 78 & 6 \\
\hline \multicolumn{3}{|l|}{$\mathrm{BMI}^{*}$} \\
\hline Underweight & 27 & 2 \\
\hline Normal & 432 & 33 \\
\hline Overweight & 313 & 24 \\
\hline Obese & 229 & 18 \\
\hline Not specified & 301 & 23 \\
\hline \multicolumn{3}{|l|}{ Children } \\
\hline Gender & 1302 & 100 \\
\hline Male & 641 & 51 \\
\hline Female & 661 & 49 \\
\hline \multicolumn{3}{|l|}{ Age (years) } \\
\hline 8 & 176 & 13 \\
\hline 9 & 192 & 15 \\
\hline 10 & 199 & 15 \\
\hline 11 & 199 & 15 \\
\hline 12 & 198 & 15 \\
\hline 13 & 164 & 13 \\
\hline 14 & 174 & 13 \\
\hline
\end{tabular}

${ }^{*}$ Calculated by dividing weight by height squared, then assigning to established categories ${ }^{(56)}$.

completing the television questionnaire ( $n$ 852), 34\% completing the Internet questionnaire $(n$ 900) and $33 \%$ completing the control questionnaire ( $n$ 852). Half of the respondents to each questionnaire were parents and half were their children. A good spread across demographic variables was achieved for both parents and children. There were no significant differences in composition of the control and intervention subgroups for any of the demographic variables for both the parent and child samples $(P>0 \cdot 05)$.

Respondents' desire to consume the advertised food products and their perceptions of appropriate consumption frequency are shown in Table 2. For both parents and children, the desire to consume the products was stronger among those in the advertising exposure conditions, although the effect was significant only among the parents $\left(F(2,1299)=6 \cdot 82, P=0 \cdot 00, \quad \eta^{2}=0 \cdot 01\right)$.
However, as expected from the single exposure, the effect size was small. Significant differences in perceived appropriate consumption frequency by exposure were found for parents $(F(2, \quad 1299)=18 \cdot 21, \quad P=0 \cdot 00$, $\left.\eta^{2}=0 \cdot 03\right)$. For children, this was limited to those exposed to the Internet advertisements $(F(2,1299)=6.719$, $\left.P=0 \cdot 00, \eta^{2}=0 \cdot 01\right)$. Importantly, no significant differences were found in relation to desire to consume the products and appropriate consumption frequency between the Internet and television groups, indicating that advertisements in these media are equally capable of influencing adults and children. In addition, there were no significant differences in children's responses by age ( 8 to 10 years: $F(2,564)=0 \cdot 672, P=0 \cdot 09 ; 11$ to 12 years: $F(2,394)=$ $0 \cdot 05, P=0 \cdot 95$; 13 to 14 years: $F(2,335)=0 \cdot 24, P=0 \cdot 79)$ or gender (girls: $F(2,658)=0.51, P=0 \cdot 60$; boys: $F(2$, $638)=1 \cdot 47, P=0 \cdot 23)$.

Given the apparent influence of a single exposure on parents' desire to consume the products, further analyses were conducted to identify demographic characteristics that were associated with this effect. Females ( $F$ (2, $\left.865)=8 \cdot 47, P=0 \cdot 00, \eta^{2}=0 \cdot 02\right)$ and those living in twoparent families were more likely to have higher levels of desire for the advertised foods $(F(2,1043)=7 \cdot 34$, $\left.P=0 \cdot 00, \eta^{2}=0 \cdot 01\right)$. The effect of education was unclear - across all education levels there was a stronger desire to consume the product in the exposure conditions, but the differences were statistically significant only for parents with undergraduate degrees (undergraduate: $F(2,685)=4 \cdot 76, P=0 \cdot 00, \eta^{2}=0 \cdot 01$; secondary school: $F(2,390)=2 \cdot 21, P=0 \cdot 11$; postgraduate: $F(2,218)=$ $0 \cdot 48, P=0 \cdot 62$ ). Across all BMI levels, desire was higher in the exposure parent groups relative to the control group, although the difference was significant among only those of normal BMI $(F(2,429)=4 \cdot 81, P=0 \cdot 01$, $\left.\eta^{2}=0 \cdot 02\right)$. However, overall levels of desire were generally stronger with increasing BMI, indicating that higher base levels may have prevented effects from being apparent among the overweight and obese groups (see Table 3).

Respondents' evaluations of the four food products were assessed across multiple attributes and aggregated as shown in Table 4. In all instances, the evaluations were more favourable among the advertising exposure groups relative to the control group. The differences in product evaluations between the exposure groups and control group were significant for all four products for the parents (fried chicken: $F(2,1299)=7 \cdot 24, P=0 \cdot 00, \eta^{2}=0 \cdot 01$; snack bar: $F(2,1299)=18 \cdot 08, P=0 \cdot 00, \eta^{2}=0 \cdot 03$; popcorn: $\quad F(2, \quad 1299)=7 \cdot 03, \quad P=0 \cdot 00, \quad \eta^{2}=0 \cdot 01$; confectionery: $\left.F(2,1299)=7 \cdot 62, P=0 \cdot 00, \eta^{2}=0 \cdot 01\right)$ and for one of the products for the children $(F(2,1299)=6 \cdot 10$, $\left.P=0 \cdot 00, \eta^{2}=0 \cdot 01\right)$. Again, there were no statistically significant differences between the television and Internet groups, indicating that both conditions were similarly capable of influencing product evaluations. 
Table 2 Advertising effects aggregated across four food products (fried chicken, popcorn, snack bar, confectionery): parents ( $n$ 1302) and their children ( $n$ 1302) aged 8-14 years participating in an online web panel survey, Australia, December 2010

\begin{tabular}{|c|c|c|c|}
\hline & \multicolumn{2}{|c|}{ Advertising exposure groups } & \multirow{2}{*}{$\begin{array}{c}\text { Control group } \\
(n 426)\end{array}$} \\
\hline & Television ( $n$ 426) & Internet $(n 450)$ & \\
\hline \multicolumn{4}{|l|}{ Parents } \\
\hline $\begin{array}{l}\text { Would you like to have this food to eat? } \\
\text { Response options: 'not at all' }=1 \text {, 'a little' }=2 \text {, 'a lot' }=3 \text {. Highest possible } \\
\text { score across four products }=12\end{array}$ & $6 \cdot 63^{\star \star}$ & $6 \cdot 59^{* *}$ & $6 \cdot 27$ \\
\hline $\begin{array}{l}\text { How often is it okay for people to have this product? } \\
\text { Response options: 'never' }=1 \text {, 'rarely' }=2 \text {, 'monthly' }=3 \text {, 'weekly' }=4 \text {, } \\
\text { 'daily' }=5 \text {. Highest possible score across four products }=20\end{array}$ & $9 \cdot 31^{* *}$ & $9 \cdot 20^{* *}$ & $8 \cdot 43$ \\
\hline \multicolumn{4}{|l|}{ Children } \\
\hline $\begin{array}{l}\text { Would you like to have this food to eat? } \\
\text { Response options: 'no' }=1 \text {, 'a little' }=2 \text {, 'a lot' }=3 \text {. Highest possible } \\
\text { score across four products }=12\end{array}$ & $6 \cdot 54$ & $6 \cdot 59$ & $6 \cdot 20$ \\
\hline $\begin{array}{l}\text { How often is it okay for people to have this product? } \\
\text { Response options: 'never' }=1 \text {, 'a little' }=2 \text {, 'a lot' }=3 \text {. Highest possible } \\
\text { score across four products }=12\end{array}$ & $5 \cdot 97$ & $6 \cdot 13^{\star *}$ & $5 \cdot 79$ \\
\hline
\end{tabular}

${ }^{\star *}$ Mean difference between exposure and control groups significant at the 0.01 level.

Table 3 Parents' desire to consume advertised food products by exposure type and demographic attributes: parents $(n$ 1302) of children aged 8-14 years participating in an online web panel survey, Australia, December 2010

\begin{tabular}{|c|c|c|c|}
\hline & \multicolumn{2}{|c|}{ Advertising exposure groups } & \multirow[b]{2}{*}{ Control group ( $n$ 426) } \\
\hline & Television ( $n$ 426) & Internet ( $n$ 450) & \\
\hline \multicolumn{4}{|l|}{ Gender } \\
\hline Male & $6 \cdot 44$ & $6 \cdot 44$ & $6 \cdot 35$ \\
\hline Female & $6 \cdot 74^{\star *}$ & $6 \cdot 65^{\star \star}$ & $6 \cdot 23$ \\
\hline \multicolumn{4}{|l|}{ Education } \\
\hline Secondary school & $6 \cdot 89$ & $6 \cdot 77$ & $6 \cdot 49$ \\
\hline Undergraduate qualification & $6 \cdot 57^{\star}$ & $6 \cdot 51^{\star}$ & $6 \cdot 17$ \\
\hline Postgraduate qualification & $6 \cdot 35$ & $6 \cdot 49$ & $6 \cdot 23$ \\
\hline \multicolumn{4}{|l|}{ Family structure } \\
\hline Two parents at home & $6 \cdot 67^{\star \star}$ & $6 \cdot 61^{\star \star}$ & $6 \cdot 26$ \\
\hline Single parent at home & $6 \cdot 43$ & $6 \cdot 51$ & $6 \cdot 33$ \\
\hline \multicolumn{4}{|l|}{ BMI } \\
\hline Normal weight & $6 \cdot 59^{\star *}$ & $6 \cdot 30$ & 6.03 \\
\hline Overweight & $6 \cdot 39$ & $6 \cdot 53$ & $6 \cdot 27$ \\
\hline Obese & $6 \cdot 79$ & $6 \cdot 82$ & $6 \cdot 72$ \\
\hline
\end{tabular}

*Mean difference between exposure and control groups significant at the 0.05 level.

${ }^{\star *}$ Mean difference between exposure and control groups significant at the 0.01 level.

\section{Discussion}

Adults are perceived to have greater immunity to advertising effects relative to children due to their greater cognitive processing abilities ${ }^{(42)}$. As a result, existing food advertising regulations are focused primarily on limiting children's exposure to advertisements for EDNP foods. The outcome is that these regulations do not consider the broader influence of the sheer quantity of advertisements for EDNP foods that has the potential to normalise EDNP food consumption patterns at a societal level ${ }^{(37,45)}$. The results of the present study indicate that advertising can lead both parents and children to evaluate products more favourably and influence their perceptions of the desirability and acceptability of food products. On the basis of a single exposure to each advertisement, product evaluations were more favourable and ratings of product desirability and appropriate consumption frequency were higher. Parents appeared to be more affected than children across these variables. Of note is that there were no significant differences in effects of advertising exposure by children's age, further suggesting that current assumptions relating to the impact of cognitive development on children's ability to withstand advertising may be inadequate to explain real-world phenomena ${ }^{(34,35)}$.

In terms of family dynamics, exposure to television advertising has been found to be associated with children's purchase requests, which in turn are related to higher levels of family conflict ${ }^{(46)}$. Active parental mediation involving communicating with children about the nature of advertising has been found to reduce such effects of advertising on children ${ }^{(31,47,48)}$. However, this is less likely to be useful where parents themselves are vulnerable to advertising and underestimate its effects. 
Table 4 Product evaluationst by exposure type: parents $(n$ 1302) and their children ( $n$ 1302) aged 8-14 years participating in an online web panel survey, Australia, December 2010

\begin{tabular}{lccc}
\hline & \multicolumn{2}{c}{ Advertising exposure groups } & \\
\cline { 2 - 3 } & $\begin{array}{c}\text { Television } \\
(n \text { 426) }\end{array}$ & $\begin{array}{c}\text { Internet } \\
(n \text { 450) }\end{array}$ & $\begin{array}{c}\text { Control group } \\
(n \text { 426 })\end{array}$ \\
\hline Parents & & & \\
Fried chicken & $10 \cdot 60^{\star *}$ & $10 \cdot 62^{\star *}$ & $10 \cdot 02$ \\
Snack bar & $11 \cdot 68^{\star *}$ & $11 \cdot 70^{\star *}$ & $10 \cdot 73$ \\
Popcorn & $12 \cdot 19^{\star *}$ & $12 \cdot 35^{\star *}$ & $11 \cdot 76$ \\
Confectionery & $12 \cdot 60^{\star *}$ & $12 \cdot 64^{\star *}$ & $12 \cdot 10$ \\
Children & & & \\
Fried chicken & $6 \cdot 60$ & $6 \cdot 56$ & 6.42 \\
Snack bar & $6 \cdot 87^{\star}$ & $6 \cdot 93^{\star *}$ & 6.53 \\
Popcorn & $7 \cdot 12$ & $7 \cdot 16$ & 6.97 \\
Confectionery & $7 \cdot 42$ & $7 \cdot 51$ & 7.30 \\
\hline
\end{tabular}

${ }^{*}$ Mean difference between exposure and control groups significant at the 0.05 level.

${ }^{\star *}$ Mean difference between exposure and control groups significant at the 0.01 level.

tParents' evaluations related to the five attributes of healthy, tasty, fun, new and convenient (four response options, highest possible score $=20$ ). Children's evaluations related to same attributes, excluding convenient (three response options, highest possible score $=12$ ).

Further work is needed to investigate the extent to which parents' granting of purchase requests for EDNP foods is related to their own susceptibility to advertising.

In their proposed food marketing defence model, Harris et $a l^{\left({ }^{(3)}\right.}$ posit that in order to withstand the persuasive appeal of advertisements, individuals need to be aware that they are being targeted, understand how they may be affected by exposure and be able and motivated to resist. While focused specifically on the effects of advertising on children, the model incorporates psychological theories developed on adult samples and thus also has relevance to the parents involved in the present study. For example, the model takes non-conscious advertising effects ${ }^{(38,39)}$ into consideration to highlight the importance of awareness in triggering the activation of effective defence mechanisms. The results of the present study indicate that while parents are likely to recognise advertisements, their understanding of the advertising effect process and hence their ability and motivation to resist may be compromised. Where understanding can be enhanced through education, this suggests a need to advise parents of the extent to which exposure and repetition can alter their perceptions and intentions below the level of conscious processing. However, should future work demonstrate that an enhanced understanding of the subconscious effects of advertisements fails to prevent ability and motivation from being compromised, greater regulatory restrictions on advertising would appear to be a more effective approach.

Regulatory restrictions would also seem justified by a growing body of work showing that Australian parents are very concerned about the promotion of unhealthy foods to children ${ }^{(49,50)}$. Kelly et al. ${ }^{(49)}$ found that parents were considerably more concerned about television advertising (82\%) than Internet advertising (36\%), which means they are likely to be underestimating the effects of Internet advertising as found in the present study. While parental concern could be expected to result in scepticism of and resistance to advertising for unhealthy foods, the greater effects on parents relative to children in the present study suggest that negative attitudes to unhealthy food advertising cannot be assumed to increase immunity. There is thus a need to consider upstream interventions such as more restrictive regulatory frameworks, especially in relation to Internet advertising.

The study results have implications for the limited coverage of current advertising regulations. The apparent ability of Internet advertising to influence evaluations of food products and enhance perceptions of desirability and acceptability demonstrates the need for effective regulatory frameworks to include this medium explicitly. Such an approach would recognise that integrated marketing across multiple media is routinely used in food promotion and hence that the full spectrum of promotional strategies should be assessed for impact ${ }^{(19)}$. The combination of television and Internet advertising is recognised to be particularly important to achieving marketing objectives ${ }^{(51)}$, making these two media among the top priorities for policy makers. Complicating the issue is the borderless accessibility of Internet advertising, which will necessitate international agreements to effectively regulate exposure ${ }^{(26)}$.

The present study has several limitations. In the first instance, social desirability effects ${ }^{(52)}$ are likely to have dampened the responses to the evaluation, desire and social norms items. Second, exposure to the food pictures is likely to have had some influence on respondents in the control group. It was necessary to provide the pictures to ensure respondents were fully aware of the products referred to in the questionnaire, but viewing the pictures would have constituted a level of priming greater than complete non-exposure ${ }^{(53)}$. Given the possibility that exposure to the pictures influenced respondents, it seems likely that the effects of exposure to the television and Internet advertisements are underestimated in the study results.

Third, the advertisements varied in the extent to which they are likely to appeal to parents and children. For example, the snack bar advertisement featured only children, while the confectionery advertisement showed a lone adult athlete. The other two advertisements depicted both adults and children. This may go some way towards explaining why the snack bar advertisement was the only one to produce a significant effect on product evaluations among child respondents. Future research could include an initial advertisement classification stage that involves assessing the extent to which appeals used in the advertisements are more child or adult focused.

Fourth, height and weight data were collected only for the parents, preventing the calculation of BMI for the children. This decision was taken to avoid parents having 
to interrupt questionnaire completion to measure their children's height and weight, which could have served as a deterrent to completion. By comparison, they would have been more likely to have known their own measurements due to greater stability of these attributes in adulthood. Future research could investigate whether advertising effectiveness is related to children's weight status to add to the limited body of knowledge on the complex relationship between food advertising, children's food preferences and children's weight status ${ }^{(3)}$.

Finally, the present study did not include children over 14 years of age. While previously it was thought that beyond this age children are likely to understand persuasive intent and be capable of activating defensive mechanisms to reduce their vulnerability ${ }^{(42)}$, more recent research suggests that adolescents lack the self-regulatory mechanisms required to withstand advertising for highly palatable foods ${ }^{(54)}$. In addition, the identity work of adolescents may make them especially susceptible to advertisements for products that can assist them in developing and communicating a sense of self ${ }^{(55)}$. Future research could include older children to investigate the relative effectiveness of advertising in different media among members of this group compared with younger children and parents.

\section{Conclusion}

Exposure to food advertising can favourably influence product evaluations, enhance the desire to consume advertised products and increase perceptions of their social acceptability. While previous work has focused on such effects among children, the present study demonstrates that parents can be also, if not more, susceptible. If meaningful improvements are to be made to the current obesogenic environment, the ability of food advertising to increase product preference and increase perceptions of acceptability at a population level needs to be recognised. In particular, given their key roles in influencing children's food preferences and diets, parents should be a specific focus of future research that aims to better understand how advertising can normalise suboptimal food consumption patterns among those who have primary care responsibility for children. Importantly, the present study also reveals for the first time the equal influence of non-traditional marketing communication approaches, making the inclusion of emerging online strategies used to promote EDNP foods a cause for concern and a necessary focus of scrutiny by researchers and policy makers.

\section{Acknowledgements}

Source offunding: This research was supported under the Australian Research Council's Linkage Projects funding scheme (project number LP0991615). Funding was also provided by Cancer Council New South Wales and Cancer Council South Australia. Conflicts of interest: The authors declare that they have no conflicts of interest. Authors' contributions: S.P. and M.R. conceptualised the study and managed data collection. L.T. conducted the statistical analysis. S.P. drafted the paper. P.Q., K.C. and K.M. provided expert input at all stages.

\section{References}

1. Access Economics Pty Limited (2008) The Growing Costs of Obesity in 2008: Three Years On. Report by Access Economics Pty Limited to Diabetes Australia. Canberra: Diabetes Australia.

2. Allender S \& Rayner M (2009) Assessing the burden of overweight and obesity: an example from the United Kingdom. Obes Facts $\mathbf{2}$, 8.

3. Harris JL, Brownell KD \& Bargh JA (2009) The food marketing defense model: integrating psychological research to protect youth and inform public policy. Soc Issues Policy Rev 3, 211-271.

4. Katan MB (2009) Weight-loss diets for the prevention and treatment of obesity. New Engl J Med 360, 923-925.

5. Magarey AM, Daniels LA, Boulton TJ et al. (2003) Predicting obesity in early adulthood from childhood and parental obesity. Int J Obes Relat Metab Disord 27, 505-513.

6. Cairns G, Angus K \& Hastings G (2009) The Extent, Nature and Effects of Food Promotion to Children: A Review of the Evidence to December 2008. Prepared for the World Health Organization by Institute for Social Marketing, University of Stirling \& The Open University, United Kingdom. Geneva: WHO.

7. McGinnis MJ, Gootman JA \& Kraak VI (2006) Food Marketing to Children and Youth: Threat or Opportunity? Washington, DC: Institute of Medicine of the National Academies.

8. World Health Organization (2006) Marketing of Food and Non-alcoholic Beverages to Children. Report of a WHO Forum and Technical Meeting, Oslo, Norway, 2-5 May 2006. Geneva: WHO; available at http://www.who.int/ dietphysicalactivity/publications/Oslo\%20meeting\%20layout \%2027\%20NOVEMBER.pdf

9. Zimmerman FJ (2011) Using marketing muscle to sell fat: the rise of obesity in the modern economy. Annu Rev Public Health 32, 285-306.

10. Hawkes C (2007) Marketing Food to Children: Changes in the Global Regulatory Environment. Geneva: WHO.

11. Australian Communications \& Media Authority (2009) Children's Television Standards 2009. Canberra: Australian Communications \& Media Authority.

12. Australian Food and Grocery Council (2009) The Responsible Children's Marketing Initiative of the Australian Food and Beverage Industry. http://www.afgc.org.au/industrycodes/advertising-to-children/qsr-initiative/qsr-core-principles. html (accessed July 2012).

13. Australian Association of National Advertisers (2009) Australian Quick Service Restaurant Industry Initiative for Responsible Advertising and Marketing to Children. http://www.aana.com.au/data/Documents/Initiatives/QSRA InitiativeforResponsibleAdvertisingandMarketingtoChildren June2009.pdf (accessed July 2012).

14. Hebden LA, King L, Grunseit A et al. (2011) Advertising of fast food to children on Australian television: the impact of industry self-regulation. Med J Aust 195, 20-24.

15. King L, Hebden L, Grunseit A et al. (2010) Industry selfregulation of television food advertising: responsible or responsive? Int J Pediatr Obes 6, 390-398. 
16. Chapman K, Kelly B \& King L (2009) Using a research framework to identify knowledge gaps in research on food marketing to children in Australia. Aust N Z J Public Health 33, 253-257.

17. Moore ES (2007) Perspectives on food marketing and childhood obesity: introduction to the special section. I Public Policy Mark 26, 157-161.

18. Shaw C (2009) (Non) regulation of marketing of unhealthy food to children in New Zealand. J $N Z$ Med Assoc 122, 76-86.

19. Calvert SL (2008) Children as consumers: advertising and marketing. Future Child 18, 205-234.

20. Federal Trade Commission (2008) Marketing Food to Children and Adolescents: A Review of Industry Expenditures, Activities, and Self-Regulation. Report to Congress, USA. http://www.ftc.gov/os/2008/07/P064504foodmktingreport. pdf (accessed July 2012).

21. Hervert G, Guerard K, Tremblay S et al. (2010) Is banner blindness genuine? Eye tracking Internet text advertising. Appl Cogn Psychol 25, 708-716.

22. Dreze X \& Hussherr FX (2003) Internet advertising: is anybody watching? I Interact Mark 17, 8-23.

23. Manchanda P, Dube JP, Goh KY et al. (2006) The effect of banner advertising on Internet purchasing. J Mark Res 43, 98-108.

24. Grier SA \& Kumanyika S (2010) Targeted marketing and public health. Annu Rev Public Health 31, 349-369.

25. Montgomery KC, Chester J, Grier SA et al. (2012) The new threat of digital marketing. Pediatr Clin North Am 59, 659-675.

26. Harris JL, Bargh JA \& Brownell KD (2009) Priming effects of television food advertising on eating behavior. Health Psychol 28, 404-413.

27. Harris JL, Speers SE, Schwartz MB et al. (2011) US food company branded advergames on the Internet: children's exposure and effects on snack consumption. J Child Media 6, 51-68.

28. World Health Organization (2010) Set of Recommendations on the Marketing of Foods and Non-Alcoholic Beverages to Children. http://whqlibdoc.who.int/publications/2010/ 9789241500210_eng.pdf (accessed July 2012).

29. Dixon HG, Scully ML, Wakefield MA et al. (2007) The effects of television advertisements for junk food versus nutritious food on children's food attitudes and preferences. Soc Sci Med 65, 1311-1323.

30. Andreyeva T, Kelly IR \& Harris JL (2011) Exposure to food advertising on television: associations with children's fast food and soft drink consumption and obesity. Econ Hum Biol 9, 221-233.

31. Buijzen M, Schuurman J \& Bomhof E (2008) Associations between children's television advertising exposure and their food consumption patterns: a household diary-survey study. Appetite 50, 231-239.

32. Harrison K, Liechty JM \& The Strong Kids Program (2012) US preschoolers' media exposure and dietary habits: the primacy of television and the limits of parental mediation. J Child Media 6, 18-36.

33. Seiders K \& Petty RD (2007) Taming the obesity beast: children, marketing, and public policy considerations. J Public Policy Mark 26, 236-242.

34. D'Alessio M, Laghi F \& Baiocco R (2009) Attitudes toward TV advertising: a measure for children. I Appl Dev Psychol 30, 409-418.

35. Rozendaal E, Buijzen M \& Valkenburg P (2009) Do children's cognitive advertising defences reduce their desire for advertised products? Communications $\mathbf{3 4}$, 287-303.

36. Dixon HG, Scully M, Wakefield M et al. (2011) Parent's responses to nutrient claims and sports celebrity endorsements on energy-dense and nutrient-poor foods: an experimental study. Public Health Nutr 14, 1071-1079.

37. Grier SA, Mensinger J, Huang SH et al. (2007) Fast-food marketing and children's fast-food consumption: exploring parents' influences in an ethnically diverse sample. J Public Policy Mark 26, 221-235.

38. Chartrand TL \& Fitzsimons GJ (2011) Nonconscious consumer psychology. J Consum Psychol 21, 1-3.

39. Fitzsimons GM, Chartrand TL \& Fitzsimons GJ (2008) Automatic effects of brand exposure on motivated behavior: how Apple makes you 'think different'. J Consum Res 35, 21-35.

40. Birch LL \& Fisher JO (1998) Development of eating behaviors among children and adolescents. Pediatrics 101, 539-549.

41. Gribble LS, Falciglia G, David AM et al. (2003) A curriculum based on Social Learning Theory emphasizing fruit exposure and positive parent child-feeding strategies: a pilot study. J Am Diet Assoc 103, 100-103.

42. John DR (1999) Consumer socialization of children: a retrospective look at twenty-five years of research. J Consum Res 26, 183-213.

43. Food Standards Agency (2007) Front-of-pack Traffic Light Signpost Labelling. Technical Guidance, Issue 2. London: FSA; available at http://www.food.gov.uk/multimedia/ pdfs/frontofpackguidance2.pdf

44. Jones S \& Fabrianesi B (2008) Gross for kids but good for parents: differing messages in advertisement for the same products. Public Health Nutr 11, 588-595.

45. Schwartz MB \& Puhl R (2003) Childhood obesity: a societal problem to solve. Obes Rev 4, 57-71.

46. Buijzen M \& Valkenburg PM (2005) Parental mediation of undesired advertising effects. I Broadcast Electron 49 , 153-165.

47. Buijzen M \& Valkenburg PM (2003) The unintended effects of television advertising: a parent-child survey. Commun Res 30, 483-503.

48. Moschis GP \& Moore RL (1982) A longitudinal study of television advertising effects. J Consum Res 9, 279-286.

49. Kelly B, Chapman K, Hardy LL et al. (2009) Parental awareness and attitudes of food marketing to children: a community attitudes survey of parents in New South Wales. J Paediatr Child Health 45, 493-497.

50. Pettigrew S, Pescud M, Rosenberg M et al. (2012) Public support for restrictions on food company sponsorship of community events. Asia Pac J Clin Nutr 21, 609-617.

51. Wang A (2011) Branding over internet and TV advertising. J Promot Manage 17, 275-290.

52. King MF \& Bruner GC (2000) Social desirability bias: a neglected aspect of validity testing. Psychol Mark 17, 79-103.

53. Janiszewski C (1993) Preattentive mere exposure effects. J Consum Res 20, 376-392.

54. Harris JL \& Graff SK (2012) Protecting young people from junk food advertising: implications of psychological research for First Amendment Law. Am J Public Health 102, 214-222.

55. Pechmann C, Levine L, Loughlin S et al. (2005) Impulsive and self-conscious: adolescents' vulnerability to advertising and promotion. J Public Policy Mark 24, 202-221.

56. Lobstein T, Baur L \& Uauy R (2004) Obesity in children and young people: a crisis in public health. Obes Rev 5, 4-85. 